\title{
Donatılı Kum Zeminlerde Düzlem Deformasyon Koşullarında Düşey Gerilme Dağılıșı
}

\author{
Bayram ATEŞ ${ }^{1}$ \\ Erol ŞADOĞLU⿱ $\mathbf{U}^{2}$
}

ÖZ

Teknolojinin gelişmesi insanoğluna daha geniş, daha ağır ve daha karmaşık yapılar yapma firsatı vermiştir. Artan ve karmaşık hale gelen yükleri zemine aktarma problemi ile karşılaşan geoteknik mühendisleri için; zemini iyileştirmek, zeminde meydana gelecek oturmaları ve gerilme dağılışlarını tespit etmek kaçınılmaz hale gelmiştir. Son yıllarda zemini iyileştirmede kullanımı artan bir yapı malzemesi olan geotekstiller, zeminlerin taşıma gücünü etkilemektedir. Zeminde meydana gelecek oturmalar açısından gerilme dağılışı ve taşıma gücü temel tasarımının en önemli parametrelerden birkaçıdır. Bu çalışmada donatılı kum zemin yüzeyine oturan model şerit temelle düzlem deformasyon koşullarında deneyler yapılmış ve uygulanan düşey yükten dolayı zeminde belirli noktalarda meydana gelen düşey gerilme artışları tespit edilmiştir. Deneysel çalışma kapsamında, üç farklı rölatif sıkılıkta geotekstille güçlendirilmiş kum tabakalarında, önceden belirlenen noktalara yerleştirilen basınç ölçerler yardımıyla düşey gerilme artışları kaydedilmiştir. Daha sonra model deney düzeneği PLAXIS 2D programı ile modellenip Mohr-Coulomb modeli ile düşey gerilme artışları belirlenmiştir. Ayrıca donatılı zeminin, Elastisite Teorisine dayalı olarak geliştirilen analitik yöntemlerle (Poulos ve Boussinesq) düşey gerilme artışları hesaplanmıştır. Deneylerle elde edilen tüm değerler incelendiğinde, rölatif sıkılığın donatılı zemindeki gerilme dağılışında etkili bir parametre olduğu belirlenmiştir. Bununla birlikte, yaygın kullanılan Elastisite Teorisine dayalı çözümlerin düşük rölatif sıkılıktaki donatılı zeminlerde oldukça hatalı sonuçlar verdiği görülmüştür.

Anahtar Kelimeler: Düşey gerilme artışı, basınç ölçer, donatılı zemin, geotekstil.

\section{ABSTRACT}

\section{Vertical Stress Distribution in Reinforced Sandy Soil in Plane Strain Conditions}

Development of technology gives the opportunity to mankind to build larger, heavier and more complex structures. For geotechnical engineers, faced with transferring the loads that

\footnotetext{
Not: Bu yazı

- Yayın Kurulu’na 1 Ağustos 2018 günü ulaşmıştır. 22 Nisan 2019 günü yayımlanmak üzere kabul edilmiştir.

- 31 Temmuz 2020 gününe kadar tartışmaya açıktır.

- https://dx.doi.org/10.18400/tekderg.449897

1 Sosyal Güvenlik Kurumu, İnşaat Emlak Şube Müdürlüğü, Trabzon - bayramates61@hotmail.com https://orcid.org/0000-0002-1251-7053

2 Karadeniz Teknik Üniversitesi, İnşaat Mühendisliği Bölümü, Trabzon - erolsadoglu@hotmail.com https://orcid.org/0000-0003-3757-5126
} 
is more complex and increasing, stabilization of soil, and determination of stress distribution and settlement has become inevitable. Geotextiles which have been used in soil stabilization increasingly in recent years affect bearing capacity of soil. Stress distribution in terms of settlement calculation and bearing capacity are some of the most important parameters for foundation design. In this study, several tests were carried out with model strip footing in plane strain conditions in reinforced cohesionless soil and the vertical stress increments occurred in the soil medium due to applied vertical surface loads were determined at several specific locations. In scope of experimental study, the sand reinforced with geotextile sheet was placed in layers in a tank with three different relative densities and vertical stress increments were measured by pressure gauges placed at predetermined locations. Subsequently, the experimental setup was modelled with PLAXIS 2D and vertical stress increments were obtained with Mohr-Coulomb model. Additionally vertical stress distribution in soil was calculated with analytical methods (Poulos and Boussinesq) based on elasticity theory. As the findings obtained from these studies were examined, it was understood that relative density is a very effective parameter for stress distribution in soils. However, the methods based on elasticity theory give rather erroneous results in low relative density reinforced soil.

Keywords:Vertical stress distribution, strain gauges, reinforced soil, geotextile.

\section{GíRiş}

Genel olarak bütün yapılar zemin üzerine, zemin içerisine, zeminden ya da bunların birleşimi biçiminde inşa edilmektedir. Yapının zemin ile teması temel vasıtasıyla gerçekleşir. Temeller üst yapıdan gelen yükleri güvenli ve ekonomik olarak zemin ortamına aktaran elemanlardır. Temellerin, yeterli güvenlikle görevlerini yerine getirmeleri taşıma gücü ve oturma koşullarını sağlamaları ile ilgilidir. Göçme anında, temel zeminin taşıyabileceği taban basıncına sınır taşıma gücü $\left(\mathrm{q}_{\text {sınır }}\right)$ ve bunun bir güvenlik katsayısına bölünmesiyle de emin taşıma gücü (zemin emniyet gerilmesi) elde edilir. Taşıma gücü koşulu, temel tabanında oluşacak basıncın (taban basıncı), bu zemine ait emin taşıma gücünden küçük olması gerekliliği olarak tanımlanabilir. Oturma, temelin dolayısıyla yapının düşey yönde hareketi olarak tanımlanır. Düşey yönde hareketin ana sebebi, yapıdan temele ve temelden zemine gelen yüklerin zemin tabakalarında yol açtığı boşlukların azalması sebebiyle oluşan sıkışmadır. Oturma koşulu da temelin veya temellerin oturmalarının izin verilebilir oturma değerlerinden küçük olması gerekliliği olarak tanımlanabilir. Taşıma gücü ve oturma kontrolü, yapıların güvenli ve ekonomik tasarımı bakımından önemlidir.

İnşaat Mühendisliğinde, genel olarak geosentetikler olarak adlandırılan polimer ürünleri (geotekstil, geomembran, geonet, geogrid, geokompozit vb.) giderek artan bir şekilde kullanılmaktadır. Geosentetik donatılı zemin, zeminin mekanik özelliklerini iyileştirmek amacı ile içerisine çekmeye dayanıklı ve zeminle arasında yeterli sürtünmeye sahip polimer malzemelerden üretilmiş geosentetikler yerleştirerek elde edilen kompozit bir yapı olarak tanımlanabilir. Geosentetik donatılı zeminlerin taşıma gücü; donatı türü, donatı uzunluğu, donatı tabakaları arasındaki mesafe, donatı tabakalarının sayısı, ilk donatı tabakası derinliği, zemin özellikleri ve yükleme durumuna bağlıdır. Patel [1], kohezyonsuz donatılı zeminde, temel şeklinin taşıma gücü ve yük-oturma davranışına etkisini araştırmış ve optimum ilk donatı tabakası derinliğini belirlemiştir. Fragaszy ve Lawton [2], zemin yoğunluğu ve donatı 
tabakalarının uzunluğunun taşıma gücüne etkisini kapsamlı bir şekilde incelemişlerdir. Guido vd. [3,4], geogrid veya geotekstil donatılı kum zemine, oturan model yüzeysel kare temelle, geotekstil-kum ve geogrid-kum arasındaki sürtünme, donatı tabakaları arasındaki mesafe, donatı tabakası genişliği, donatı tabakası sayısı ve donatı çekme mukavemeti parametrelerinin taşıma gücüne etkisi belirlemeye çalışmıştır. Khing vd. [5] geogrid tabakalarıyla güçlendirilmiş kum zemine oturan, model yüzey şerit temelin taşıma gücü sonuçlarını sunmuşlardır. Benzer şekilde çok sayıda çalışma yürütülerek, farklı donatı, zemin ve yükleme koşullarının taşıma gücü üzerindeki etkisi deneysel olarak araştırılmıştır [ 6-15].

Oturma, yapının düşey yönde hareketidir. Suya doygun kohezyonlu zeminlerde oturma hesaplanması, Terzaghi Konsolidasyon Teorisi'ne göre yapılır [16]. Taneli zeminlerde oturmalar, daha çok arazi deneylerinin sonuçlarından tahmin edilir. Oturma hesaplarında gelenekselleşmiş bir diğer yaklaşım, zemin ortamının ideal elastik kabul edilmesidir. Donatılı zeminlerde, genellikle taneli zeminler kullanılmakla birlikte bu tür zeminler arazi deneyleri yapmaya uygun değildir. Ayrıca donatılı zeminlerin tabakalı anizotropik yapısı, ideal elastik kabulü yapmaya uygun değildir. Janbu [17] tarafından önerilen Teğet Modulü Yaklaşımı, lineer ve lineer olmayan zemin deformasyonlarının belirlenmesinde kullanılmaktadır. $\mathrm{Bu}$ yaklaşımda şekil değiştirme $(\varepsilon)$ aşağıdaki bağıntı ile tanımlanır.

$$
\varepsilon=\frac{1}{m \alpha^{\prime}}\left[\left(\frac{\sigma_{z o}^{\prime}+\Delta \sigma_{z}^{\prime}}{\sigma_{r e f}}\right)^{\alpha}-\left(\frac{\sigma_{z o}^{\prime}}{\sigma_{r e f}}\right)^{\alpha}\right]
$$

Burada, $\mathrm{m}$ : $\quad$ boyutsuz modül sayıs1,

$\alpha^{\prime}$ : boyutsuz basınç üssü,

$\sigma_{\text {ref: }} \quad$ referans basınç $(100 \mathrm{kPa})$,

$\sigma_{z 0}^{\prime}$ : yüklemeden önceki düşey efektif gerilme,

$\Delta \sigma_{z}^{\prime}$ : düşey efektif gerilme artışıdır.

İlave yüklemeye maruz bir donatılı zemin tabakasında oluşacak oturma aşağıdaki bağıntı ile elde edilebilir.

$$
\Delta h=\int_{0}^{H} \varepsilon d z=\sum_{i=1}^{n} \varepsilon_{i} \Delta z_{i}
$$

Burada, $\Delta h$ : oturma, $H$ : tabaka kalınlığıdır. Çeşitli zemin tipleri için boyutsuz modül sayısı ve basınç üssü değerleri önerilmektedir [18]. Donatı kullanılması zeminde gerilme dağılış1 üzerinde etkili olduğundan donatılı zemin tabakalarındaki oturmalar donatısız durumdan farkl111k gösterir.

Donatılı zeminlerle ilgili yürütülen bazı çalışmalarda, donatı kullanımın aynı koşullardaki donatısız zemine göre, yüzey yükleri sebebiyle oluşan oturmaları azalttığı ifade edilmektedir. Bu çalışmalarda donatılı zeminlere ait yük-oturma eğrisinin daha dik bir hal aldığı, başka bir 
değişle donatılı zeminlerde belirli bir oturma için donatısız zeminlere göre daha büyük yüklerin uygulanması gerektiği deneysel olarak gözlenmiştir [19-23]. Hatta, bazı araştırmacılar donatı kullanılmasının temellerde oluşan farklı oturmaları azalttığını deneysel ve teorik çalışmalarla göstermişlerdir [24-26]. Zeminlerde oluşan oturmalar, esasen boşluk hacminin azalması neticesinde ortaya çıkmaktadır. Çünkü yapı yüklerinin tesiri altındaki zemin tanelerinin sıkışması ihmal edilebilir mertebededir. Benzer şekilde donatılı zeminlerin oturmasında donatının sıkışmasının katkısı, donatı tabakalarının toplam kalınlığının yüzey yüklerinden etkilenen tabaka kalınlığına nispeten çok küçük olması sebebiyle ihmal edilebilir. Bu durumda, donatılı zeminlerde belirli bir yüke karşılık gelen oturmaların aynı durumdaki donatısız zemine göre daha az olması gerilme dağılışında meydana gelen değişimle açıklanabilir. Başka bir anlatımla, donatı kullanılması yüzey yükünden dolayı oluşan gerilme artışlarını daha geniş bir alana yaymaktadır.

Boussinesq [27]; homojen, izotrop, lineer elastik ve Poisson oranının 0,5 olduğu yarı sonsuz ortamda tekil yükten dolayı oluşan gerilme artışları için bir çözüm elde etmiştir. Westergaard [28]; lineer elastik, izotrop, yarı sonsuz ve yatay doğrultudaki normal ve kayma şekil değiştirmelerinin sıfır kabul edildiği ortamda düşey tekil yük etkisiyle oluşan gerilme artışları için bir çözüm elde etmiştir. Çeşitli araştırmacılar tarafindan, tekil yük için elde edilen bu çözümler farklı yüzey yüklemeleri için integre edilerek, bu yüzey yüklerine ait çözümler elde edilmiştir [29-32]. Poulos [33] sınırlı kalınlıktaki lineer elastik tabaka yüzeyine etkiyen üniform şerit yük için bir çözüm elde etmiştir. Keskin vd. [34] orta sıkı kum zemine oturan model kare temelin orta noktasının altındaki çeşitli derinliklerde oluşan düşey gerilme artışlarını deneysel olarak belirlemiştir. Bu çalışmada deneysel ölçümlerle elde edilen düşey gerilme artışlarının Boussinesq ve Nümerik (linear elastik) çözümlerden oldukça fazla olduğu, yine Drucker-Prager elastoplastik modeli kullanılarak elde edilen nümerik çözümün deneysel ölçümlere en yakın sonuçlar verdiği tespit edilmiştir.

Geosentetik donatılı zeminlerde yüzey yüklerinden dolayı oluşan gerilme artışları ile ilgili az sayıda çalışma bulunmaktadır. Chen [35], siltli kil zeminde yaptığı deneylerde donatı çekme mukavemeti ve tabaka sayısı arttıkça düşey gerilme artışlarının Boussinesq çözümüyle uyumlu bir davranış gösterdiği ve düşey gerilme artışlarının uygulanan taban basıncı büyüklüğüne bağlı olarak farklı davranışlara sahip olduğunu gözlemlemiştir. Çiçek vd. [36] model şerit temel altındaki geotekstil donatılı orta sıkı kum zeminde oluşan düşey gerilme artışları deneysel olarak incelemiş ve Westergaard çözümünün deneysel ölçümlerle daha uyumlu olduğunu görülmüştür.

Donatılı zeminler arazi deneyleri yapmaya uygun değildir. Bu tür zeminlerde yapı yüklerinden oluşacak oturmalar, zemin ortamının sıkışma özellikleri ve yapı yüklerinde kaynaklanan gerilme artışlarının tespiti ile hesaplanabilir. Oluşan gerilmelerin şiddetinin ve dağılımının bilinmesi, birçok geoteknik probleminin çözümü ve projelerin tasarımında da oldukça önemlidir. Ancak donatılı zeminlerde gerilme dağılışı ile ilgili çalışmalar oldukça sınırlıdır. Dolayısıyla bu çalışmada, donatılı kum zemine oturan merkezi yüklü bir model şerit temelin yük-gerilme dağılışı ilişkileri; deneysel, analitik ve nümerik olarak incelenmiştir. Bu amaçla, öncelikle düzlem deformasyon koşullarını sağlayan bir deney düzeneğinde yükleme deneyleri yapılarak, basınç ölçerler yardımıyla yük-gerilme dağılışı ilişskisi belirlendi. Ölçülen düşey gerilme artışları, Elastisite Teorisine dayalı Poulos ve Boussinesq çözümleri ile sonlu elemanlar yöntemi yardımıyla Mohr-Coulomb modelinden elde edilen sonuçlarla karşılaştırıldı ve yorumlandı. 


\section{DENEYSEL ÇALIŞMA}

Geotekstil donatılı zemine oturan merkezi yüklü şerit temelin, farklı rölatif sıkılıklarda ve farklı derinliklerde gerilme dağılışlarını gözlemlemek için bir deney düzeni yapılmıştır. Deney düzeni; deney tankı, model şerit temel, yükleme düzeni, kum yüzeyini düzleme aleti, basınç ölçerler ve kum ana parçalarından oluşmaktadır. Bunlara ilaveten, deneylerde kumun sıkıştırılması için genişliği, deney tankı genişliğine eşit olan bir ahşap tokmak kullanılmıştır. Deneyler, K.T.Ü. İnşaat Mühendisliği Bölümünün Geoteknik Laboratuarında gerçekleştirilmiş olup, laboratuarda bulunan üç eksenli deney aletinin presi (yükleme düzeni), yük halkaları, deformasyon ölçüm saatleri ile dijital fotoğraf makinesi kullanılmıştır. Deney düzeninin şeması Şekil 1'de görülmektedir. Deney tankının alt ve yan yüzleri sert ağaçtan üretilmiş bir çerçeve olup; bu ahşaba cam levhaları yerleştirilebilmesi için "L" biçimli kanallar açılmıştır. Ön ve arka yüzler, kırılma yüzeylerini gözlemlenebilmesi ve fotoğraf çekilebilmesi için 20 mm kalınlığındaki cam plakalardan oluşturulmuştur. Bu kalın cam plakalar yan sürtünmeleri mümkün mertebe azaltmak; aynı zamanda yükleme esnasında şerit temelin eksenine dik rijit düzlemler oluşturmada faydalı olmuşlardır. Deney tankının içi bir dikdörtgenler prizması olup, uzunluğu $0,90 \mathrm{~m}$, genişliği $0,10 \mathrm{~m}$ ve yüksekliği 0,65 metredir.

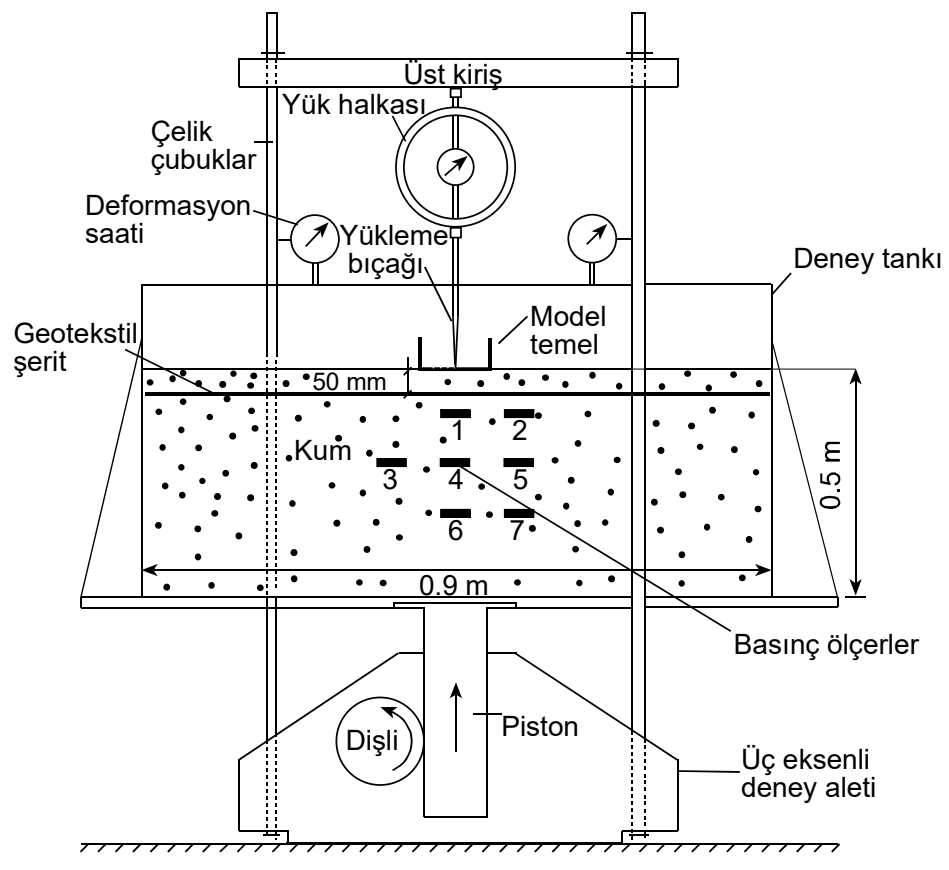

Şekil 1 - Deney düzeninin şeması

Model temelin genişliği $100 \mathrm{~mm}$, uzunluğu $100 \mathrm{~mm}$ ve yan yüzlerinin yüksekliği $70 \mathrm{~mm}$ olup, $5 \mathrm{~mm}$ kalınlığında çelik levhalardan üretilmiştir. Model temelin cama temas eden ön ve arka yüzlerine $2 \mathrm{~mm}$ kalınlığında sert plastik tabakalar yapıştırılmıştır. Bununla, camla 
temel yan yüzleri arasına kum tanelerini girmesinin engellenmesi ve camla temelin sürtünmesinin azaltılması amaçlanmıştır. Bu plastik yüzeyler deney esnasında yağlanarak temelle cam arasındaki sürtünme en aza indirilmiştir. Model temelin tabanında merkezi yükleme yapabilmek için V şeklinde yarık açılmıştır. Yükleme bıçağının oturduğu oyuğun kalınlığının küçük olmasına dikkat edilmiştir. Tam sürtünmeli ve pratikteki koşullara uygun olarak kalın bir zımpara kâğıdı temel tabanına yapıştırılmıştır. Şekil 2'de model şerit temelin bir şeması gösterilmektedir.

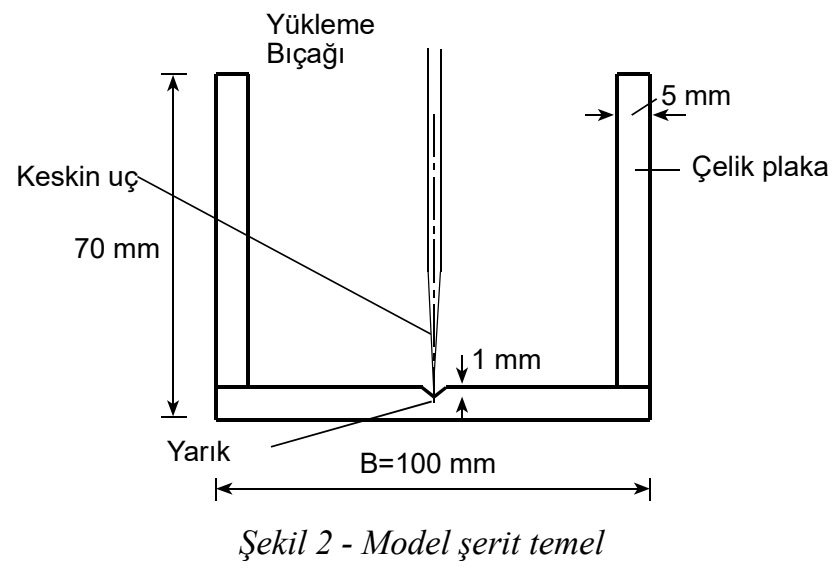

Deneylerde, İyidere ilçesi (Rize)'nin bitişiğindeki doğu sahilinden alınan kum kullanılmıştır. Kum, öncelikle içindeki yabancı maddeleri ayrıştırmak için 4 No'lu elekten geçirilmiştir ve sonrasında 200 No'lu elekte yıkanmış ve kurutulmuştur. Kumun, ilgili deneylerle belirlenmiş bazı geoteknik özellikleri Tablo 1'de gösterilmiştir. Kumun tane çapları 0,2-4,0 mm arasında (iri-orta) olup, Birleştirilmiş Zemin Sınıflandırma Sistemine göre sınıfı kötü derecelenmiş kumdur (SP). Rölatif sıkılığın Dr=0.25, 0.50, 0.75 olmas1 için kumun kuru birim hacim ağırlığı aşağıdaki bağıntı ile hesaplanmıştır. Farklı rölatif sıkılıktaki deney kumuna ait içsel sürtünme açısı değerleri kesme kutusu deneyi ile elde edilmiştir.

$\mathrm{D}_{\mathrm{r}}=\frac{\gamma_{\mathrm{kmax}}}{\gamma_{\mathrm{k}}}\left(\frac{\gamma_{\mathrm{k}}-\gamma_{\mathrm{kmin}}}{\gamma_{\mathrm{kmax}}-\gamma_{\mathrm{kmin}}}\right)$

Tablo 1 - Deney kumunun geoteknik özellikleri

\begin{tabular}{|l|c|c|}
\hline \multicolumn{1}{|c|}{ Özellik } & Birim & Değer \\
\hline Tane özgül yoğunluğu, $\mathrm{G}_{\mathrm{s}} \quad$ (ASTM D854-14, [37]) & - & 2.66 \\
\hline Maksimum kuru yoğunluk, $\rho_{\mathrm{kmax}}$ (ASTM D4253-16, [38]) & $\mathrm{Mg} / \mathrm{m}^{3}$ & 1.658 \\
\hline Minimum kuru yoğunluk, $\rho_{\mathrm{kmin}} \quad$ (ASTM D4254-16, [39]) & $\mathrm{Mg} / \mathrm{m}^{3}$ & 1.395 \\
\hline Efektif çap, $\mathrm{D}_{10}$ & $\mathrm{~mm}$ & 0.58 \\
\hline
\end{tabular}


Tablo 1 - Deney kumunun geoteknik özellikleri (devam)

\begin{tabular}{|c|c|c|}
\hline Özellik & Birim & Değer \\
\hline $\mathrm{D}_{30}$ & $\mathrm{~mm}$ & 0.80 \\
\hline $\mathrm{D}_{60}$ & $\mathrm{~mm}$ & 0.95 \\
\hline Üniformluluk katsayısı, $\mathrm{C}_{\mathrm{u}}$ & - & 1.64 \\
\hline Eğrilik katsayısı, $\mathrm{C}_{\mathrm{r}}$ & - & 1.16 \\
\hline Kuru yoğunluk $\left(\mathrm{D}_{\mathrm{r}}=0.75\right), \rho_{\mathrm{k} 0.75}$ & & 1.590 \\
\hline Kuru yoğunluk $\left(\mathrm{D}_{\mathrm{r}}=0.50\right), \rho_{\mathrm{k} 0.50}$ & $\mathrm{Mg} / \mathrm{m}^{3}$ & 1.520 \\
\hline Kuru yoğunluk $\left(\mathrm{D}_{\mathrm{r}}=0.25\right), \rho_{\mathrm{k} 0.25}$ & & 1.450 \\
\hline İçsel sürtünme açısı, $\phi\left(\right.$ Kesme kutusu, $\left.D_{r}=0.75\right)$ & & 42.30 \\
\hline $\begin{array}{l}\text { İçsel sürtünme açısı, } \phi\left(\text { Kesme kutusu, } D_{r}=0.50\right) \text { ( ASTM D3080 / } \\
\text { D3080M-11, [40]) }\end{array}$ & Derece & 39.95 \\
\hline İçsel sürtünme açısı, $\phi\left(\right.$ Kesme kutusu, $\left.D_{r}=0.25\right)$ & & 37.42 \\
\hline
\end{tabular}

Deneylerde, tankın plandaki iç alanına $(0,10 \mathrm{~m}$ x 0,90 m) eşit büyüklükte bir örgülü geotekstil temel tabanından itibaren 0,05 m (0,5B) derinlikte yerleştirilmiştir. Bu geotekstil Salteks Ltd. Şti., İstanbul-Türkiye tarafından sağlanmıştır. Örgülü geotekstil ile ilgili bazı bilgiler, Tablo 2'de görülmektedir.

Tablo 2 - Örgülü geotekstilin bazı özellikleri

\begin{tabular}{|l|c|l|}
\hline Özellik & Birim & Değer \\
\hline Tip & ----- & Örgülü \\
\hline Polimer & ----- & Polipropilen \\
\hline Ağırlık & $\mathrm{g} / \mathrm{m}^{2}$ & 430 \\
\hline Çekme Dayanımı (DIN 53857) & $\mathrm{kN} / \mathrm{m}$ & 8.6 \\
\hline Kopma anındaki uzaması (boyuna) & $\%$ & 14 \\
Kopma anındaki uzaması (enine) & $\%$ & 14 \\
Başlangıç tanjant modülü & $\mathrm{kN} / \mathrm{m}$ & 218.9 \\
\hline
\end{tabular}

Donatılı zemine uygulanan yüzey yüklerinden dolayı meydana gelecek düşey gerilme artışlarını ölçebilmek amacıyla kullanılan yöntemlerden biri de zemin içerisinde gerilme ölçülecek derinliklere basınç ölçerler yerleştirilmesidir. Basınç ölçerler vasıtasıyla gerilme ölçmenin diğer yöntemlere göre en önemli avantaj1, gerilme değerlerinin doğrudan ölçülebilmesidir. Şekil 3'te bu deneysel çalışmada kullanılan Tokyo Sokki Kenkyujo Co. Ltd. firması tarafından üretilen KDE-500KPA model $50 \mathrm{~mm}$ çapında ve $500 \mathrm{kPA}$ kapasiteli basınç ölçer görülmektedir. Basınç ölçerlerde ölçülen gerilme değerleri, 8 kanal girişli veri 
toplama cihazı ve aygıt geçidi yardımıyla bilgisayara aktarılmıştır. Bu veriler CoDA Locomotive programı yardımıyla sayısal değerlere dönüştürülmüştür.

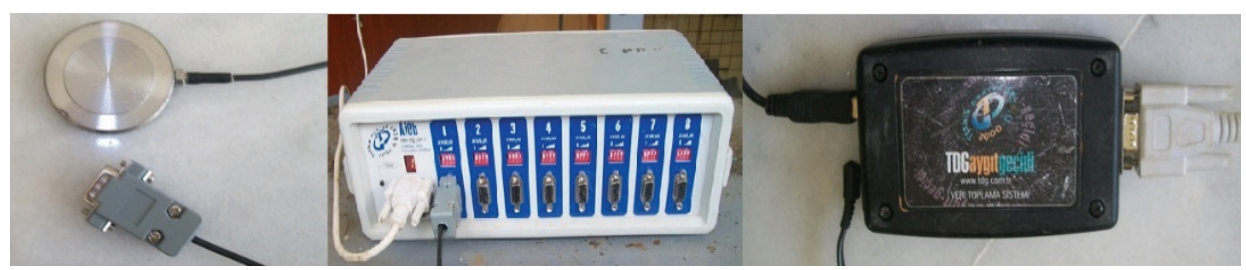

Şekil 3 - Deneylerde kullanılan basınç ölçer, veri toplama ünitesi ve aygıt geçidi

Deneyler düzlem şekil değiştirme koşullarında yapılmıştır. Düzlem şekil değiştirmenin oluşabilmesi için iki koşulun sağlanması gerekir. Bunlar: a) Şekil düzlemine dik doğrultudaki şekil değiştirme sıfır olmalıdır, b) Şekil düzlemine paralel yüzeylerde kayma gerilmeleri sıfır olmalıdır. Bu şartları sağlanması için, aynı kesit özellikleri sonsuz uzunluktaki bir yapıda olması gerekir. $\mathrm{Bu}$ çalışmada kullanılan deney düzeneğinin düzlem şekil değiştirme koşullarını sağlaması içinde benzer şekilde, model temel ekseni doğrultusunda (deney tankı düzlemine dik doğrultudaki) şekil değiştirme sıfır olmalı; deney tankının içindeki zemin ile deney tankı yan yüzlerini oluşturan camlar arasındaki sürtünme sıfır olmalıdır.

Deneylerde, teorik olarak rijit ön ve arka yüzleri sağlamak imkânsızdır. Bu durumda şekil düzlemine dik doğrultudaki şekil değiştirmeleri sınırlamak ve kontrol altında tutmak gereklidir. Kirkpartick ve Yanikian [41] yaptıkları çalışmalarda yan duvarların hareketlerinin model genişliğinin \% 0,1'inden küçük olması durumunda elde edilen sonuçların gerçek düzlem şekilde değiştirme sonuçlarını yansıttığını belirtmişlerdir. Bu çalışmada yapılan deneylerde zemin direk olarak cama temas etmektedir. Kirkpatrick ve Uzuner [42] cam-kum temasında, orta sıkı zemine oturan yüzey temelinde $\left(\mathrm{D}_{\mathrm{f}}=0\right)$ temel genişliğinin model genişliğine oranının 1 olması durumunda yan sürtünmesinin taşıma gücüne etkisinin \%10'dan küçük olacağını göstermişlerdir. $\mathrm{Bu}$ çalışmada yapılan gerilme dağılışı deneylerinde, zemin tam mobilize olmadığı için yan sürtünmesinin etkisi taşıma gücü deneylerinden daha az olacaktır.

Deney tankına kum, ön ve arka yüzlerinde çizilmiş ağlar takip edilerek tabakalar halinde doldurulmuştur. Her tabakaya $\mathrm{D}_{\mathrm{r}}=0,75$ elde etmek için $7149 \mathrm{~g}, \mathrm{D}_{\mathrm{r}}=0,50$ elde etmek için 6831 $\mathrm{g}, \mathrm{D}_{\mathrm{r}}=0,25$ elde etmek için $6542 \mathrm{~g}$ kum serbestçe dökülmüştür. Bu serilen gevşek tabakayı üniform bir kalınlığa getirmek için kum yüzeyi düzeltme aleti kullanılmıştır. Kum yüzeyi düzeltme aleti ile dikkatli bir şekilde aynı tabaka kalınlığı (yaklaşık $55 \mathrm{~mm}$ ) elde edilmiştir. Bu aşamadan sonra ahşap hafif bir tokmak yardımıyla tabaka kalınlığ $50 \mathrm{~mm}$ 'ye indirilmiştir. Böylece deneylerde planlanmış olan rölatif sıkılıklar $\left(\mathrm{D}_{\mathrm{r}}=0.75,0.50,0.25\right)$ elde edilmiştir. Kum tabakası serme ve sıkıştırma işlemi devam ederken belirlenen noktalarda gerilme artışını ölçmek için basınç ölçerler yerleştirilmiştir (Şekil 1). Son zemin tabakası oluşturulduktan sonra model temel düzeneğe yerleştirilmiştir. $\mathrm{Bu}$ işlemlerden sonra sabit hızla model temele, $100 \mathrm{kPa}$ 'lık taban basıncı oluşacak şekilde deformasyon kontrollü yükleme yapılmıştır. Ayrıca, sıkıştırılan zeminin homojenliği deney tamamlandıktan sonra 
deney tankına yerleştirilen numune kapları ile kontrol edilmiştir. Deneyler, her bir rölatif sıkılık için üç defa tekrarlanmış, sonuçlar kayıt altına alınmıştır.

\section{ANALITIK VE NÜMERIK ÇALIŞMALAR}

Boussinesq [27] tarafından tekil yük için elde edilen çözüm, sonsuz uzunlukta ve B genişliğinde üniform şerit yük için integre edilerek Bağıntı (4) ve (5) elde edilir. Bu bağıntılar, Boussinesq çözümünde Poisson oranı 0.5 kabul edildiği için Poisson oranından bağımsızdır. Bağıntı (4) düşey gerilme artışını ve Bağıntı (5) ise yatay gerilme artışını vermektedir.

$$
\begin{aligned}
& \Delta \sigma_{\mathrm{z}}=\frac{\mathrm{q}}{\pi}[\alpha+\sin \alpha \cos (\alpha+2 \beta)] \\
& \Delta \sigma_{\mathrm{X}}=\frac{\mathrm{q}}{\pi}[\alpha-\sin \alpha \cos (\alpha+2 \beta)]
\end{aligned}
$$

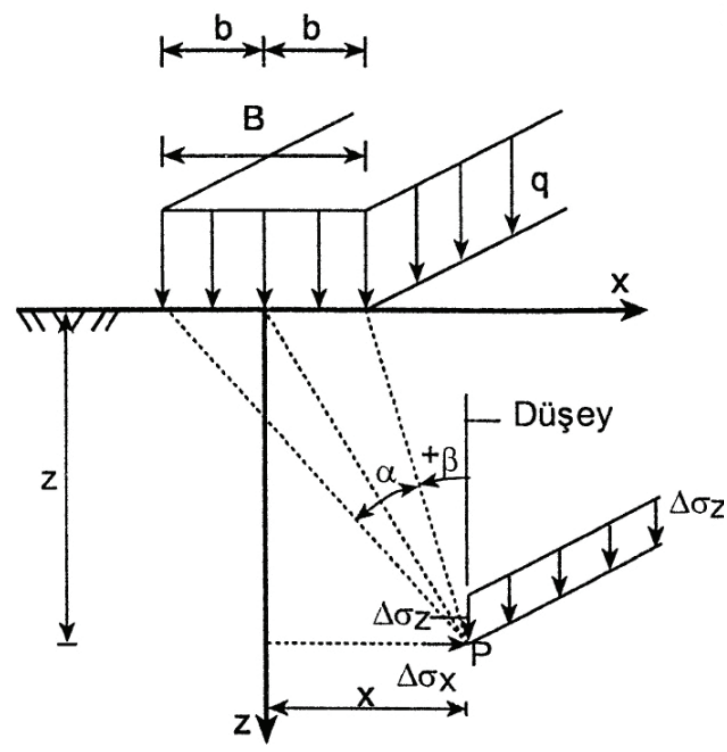

Şekil 4 - Üniform Şerit yükten kaynaklanan düşey ve yatay gerilme artışları

Poulos [33] tarafından, tam sürtünmeli rijit tabanın üzerine oturan sınırlı kalınlıktaki elastik tabakadaki gerilme ve yer değiştirmelerin analitik olarak elde edilmesi problemi çözülmüştür. Sınırlı tabakaya etki eden B genişliğinde q üniform şerit yükünden meydana gelecek düşey gerilme artışları, $\Delta \sigma_{z}$, aşağıda bağıntı ile elde edilebilir (Şekil 5). 


$$
\Delta \sigma_{\mathrm{z}}=\left(\frac{\mathrm{q}}{\pi}\right) \times \mathrm{I}_{\mathrm{st}}
$$

Burada, q: uygulanan yükün siddetini ve $\mathrm{I}_{\mathrm{st}}$ : etki faktörünü göstermektedir.

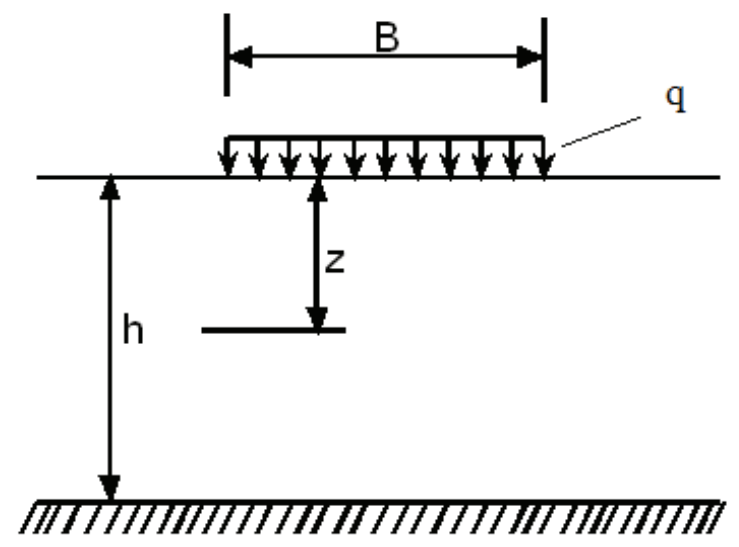

Şekil 5 - Üniform şerit yüzey yükünün yüklendiği sınırlı elastik tabaka

Tekil yük için elde edilen çözüm, çeşitli yüzey yükleri için integre edilerek etki faktörleri ( $\left.\mathrm{I}_{\mathrm{st}}\right)$ eğrileri elde edilmiştir. Şekil 6'da, Poisson oranının 0,2 ve 0,4 olduğu üniform şerit yük durumu için $\mathrm{z} / \mathrm{h}$ ve $\mathrm{B} / \mathrm{h}$ değerlerine bağli olarak etki faktörleri verilmiştir.
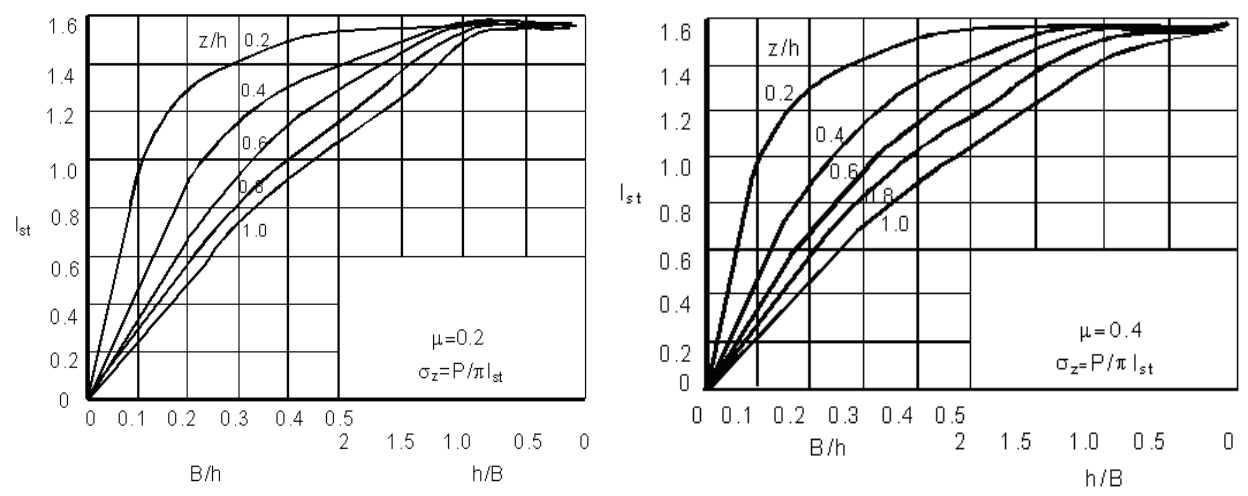

Şekil 6 - Üniform şerit yük için Poisson oranı( $\mu$ ) 0,2 ve 0,4 için etki faktörü eğrileri

Poulos tarafından önerilen sınırlı tabaka çözümleri Poisson oranına bağlıdır. Deneylerde kullanılan kumun elastisite modülü (E) ve Poisson oranının ( $\mu$ ) belirlenmesi amacıyla her bir rölatif sıkılık değeri için konsolidasyon ve üç eksenli basınç deneyleri yapılmıştır (Tablo 3). 
Tablo 3 - Kuma ait Poisson oranı ve elastisite modülü değerleri

\begin{tabular}{|c|c|c|}
\hline Rölatif S1kılık $\left(\mathrm{D}_{\mathrm{r}}\right)$ & Poisson Oranı $(\mu)$ & Elastisite Modülü $(\mathrm{E})$ \\
\hline 0.75 & 0.36 & 33579 \\
\hline 0.50 & 0.30 & 19895 \\
\hline 0.25 & 0.20 & 14282 \\
\hline
\end{tabular}

Nümerik yöntemler, son yıllarda geoteknik mühendisliği problemlerinin çözümünde sıklıkla kullanılmaktadır. Nümerik yöntemlerde, uygun zemin modelinin seçimi ve model parametrelerinin belirlenmesi nümerik analizin başarısı açısından önem arz etmektedir. Mohr-Coulomb elasto-plastik modeli, Mohr-Coulomb kırılma hipotezindeki kayma mukavemeti parametrelerini (kohezyon, içsel sürtünme açısı) kullanarak akma yüzeyini tanımlayan elastik-ideal plastik bir malzeme modelidir. $\mathrm{Bu}$ modelde plastik şekil değiştirmeler, akma yüzeyini tanımlayan fonksiyondan farklı bir plastik potansiyel fonksiyonu ile tanımlanır. Mohr-Coulomb modelinin zayıf yönü, tek bir rijitlik parametresi kullanmasıdır. Bu sebeple malzeme modeli, deformasyon problemlerinde yanıltıcı sonuçlar verebilmektedir. Bu çalışmada, PLAXIS 2D [43] programı yardımıyla deneysel çalışmadaki yükleme durumunun nümerik bir modeli oluşturulmuştur (Şekil 7). Kum zemin için, MohrCoulomb modeli tanımlanmıştır (Tablo 1 ve 3). Geotekstil tabakada, deney sırasında herhangi bir kopma ve plastik deformasyon gözlenmediği için izotropik-elastik çekmeye çalışan elemanlar olarak modellenmiştir (Tablo 2).

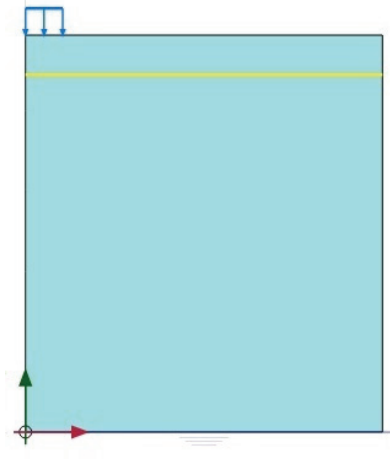

(a)

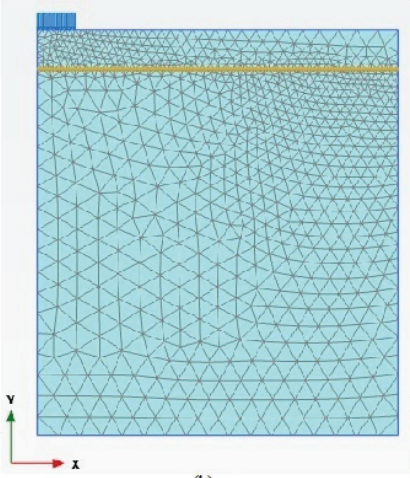

(b)

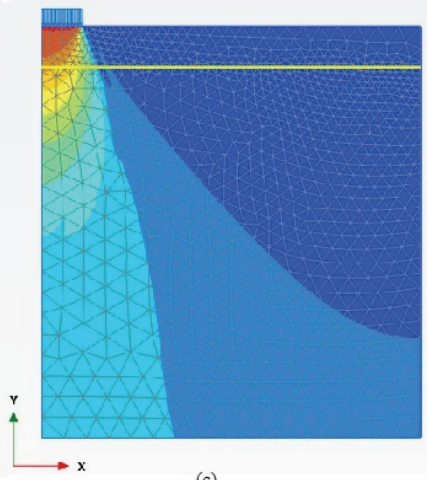

(c)

Şekil 7 - Nümerik analiz (a) Model (b) Sonlu elemanlar ă̆ı (c) Düşey gerilme dağılışı

\section{BULGULAR VE TARTIŞMA}

Bu çalışmanın esas gayesi, donatılı kum zemin yüzeyine etkiyen üniform şerit yük sebebiyle oluşan düşey gerilme artışlarının, rölatif sıkılık ile değişiminin araştırılmasıdır. Bu amaçla oluşturulan deney düzeneğine, üç farklı rölatif sıkılıkta $\left(\mathrm{D}_{\mathrm{r}}=0.75,0.50\right.$ ve 0.25$)$ kum yerleştirilmiştir. Her rölatif sıkılık için belirli miktarda kum tabakalar halinde sıkıştırılarak homojen bir zemin kütlesi elde edilmiştir. Kum tabakalar oluşturulurken, Şekil 8'de gösterilen lokasyonlara basınçölçerler yerleştirilmiş ve son tabaka yerleştirilmeden önce 
geosentetik malzeme serilmişstir. Son tabakada serildikten sonra model temel merkezi olarak kademe kademe yüklenerek $100 \mathrm{kPa}$ 'lı ortalama taban basıncı uygulanmıştır. Her bir deney üç kez tekrarlanmıştır.

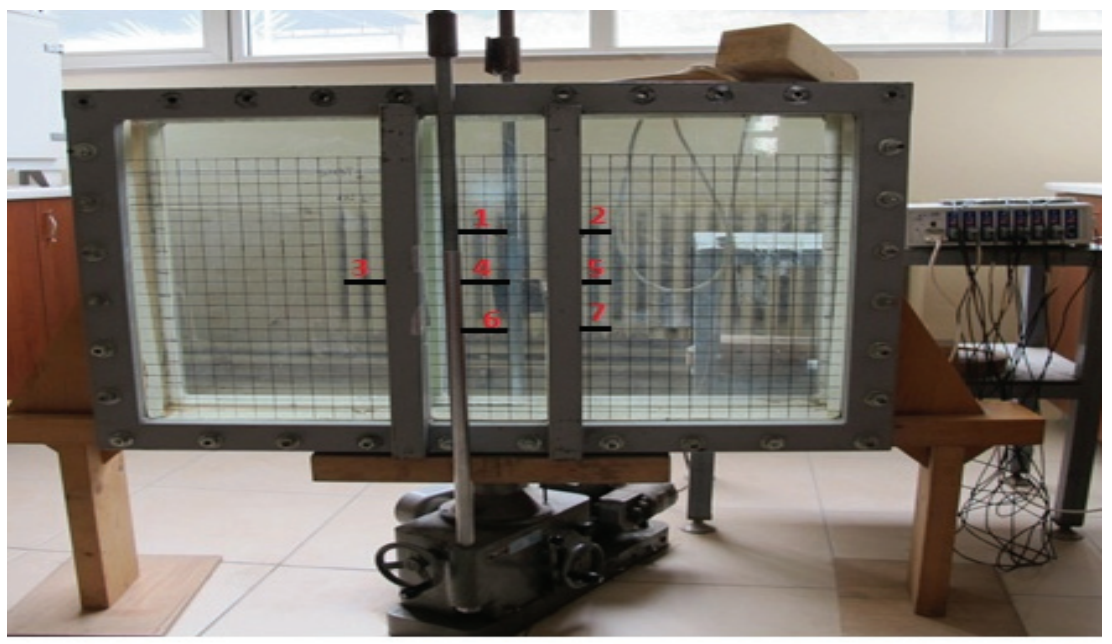

Şekil 8 - Deney tankında basınçölçerlerin yerleştirildiği yerler

Basınç ölçerlerin gerilme dağılışı üzerinde etkisi ve deney düzeneğinin simetrikliğinden kaynaklı hataların tespiti için 3 ve 5 No'lu basınç ölçerler simetrik yerleştirilmiştir. 3 ve 5 No'lu basınç ölçerlerde ölçülen gerilme artışlarının çok yakın olması deneylerin başarılı yürütüldüğünü ve deneysel hataların ihmal edilebilir düzeyde olduğunu göstermektedir.

Tablo 4 - 3 ve 5 No'lu basınçölçerlerde ölçülen düşey gerilme artışları

\begin{tabular}{|c|c|c|}
\hline \multirow{2}{*}{$\begin{array}{c}\text { Rölatif Sıkılık } \\
\left(D_{\mathrm{r}}\right)\end{array}$} & \multicolumn{2}{|c|}{ Düşey gerilme artışları } \\
\cline { 2 - 3 } & 3 No'lu Basıçölçer & 5 No'lu Basıçölçer \\
\hline 0.75 & 13 & 13 \\
\hline 0.50 & 9 & 10 \\
\hline 0.25 & 6 & 7 \\
\hline
\end{tabular}

Model şerit temelin merkezi altında bulunan 1, 4 ve 6 No'lu basınç ölçerlerde ölçülen düşey gerilme artışı ile Mohr-Coulomb modeli, Boussinesq ve Poulos çözümleri ile hesaplanan düşey gerilme artışlarının rölatif sıkılık ile değişimi Şekil 9'da görülmektedir. 1, 4 ve 6 No'lu basınçölçerde yapılan ölçümlerde, rölatif sıkılık arttıkça ilave gerilmenin azaldığ1 görülmektedir. Rölatif sıkılığın yüksek olduğu durumda, sığ derinliklerde (z/B=1), Poulos ve Boussinesq çözümü ile deneysel ölçümler birbiriyle uyumludur. Fakat, sığ derinlikte rölatif sıkılık düşük olduğunda, Poulos ve Boussinesq çözümü ile deneysel ölçümler arasında ciddi 
farklılıklar vardır. Genel olarak, Mohr-Coulomb modeliyle yapılan nümerik analizden elde edilen sonuçlar, deneysel ölçümlere en yakın değerlerdir. Bunun sebebi, kum zeminlerde yüklü alanın civarında normal gerilmelerin düşük olduğu bölgelerde plastikleşmelerin oluşması ve bu durumun elastisite teorisine dayalı yöntemlerde göz önüne alınamamasıdır.

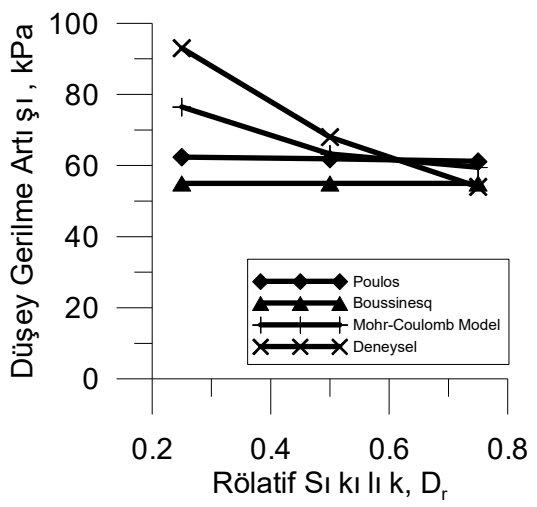

(a)

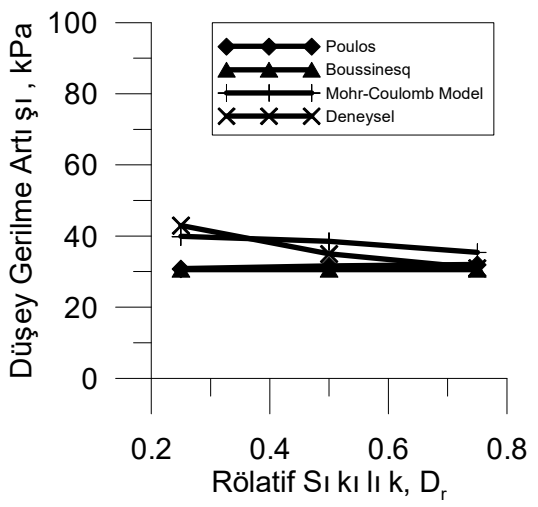

(b)

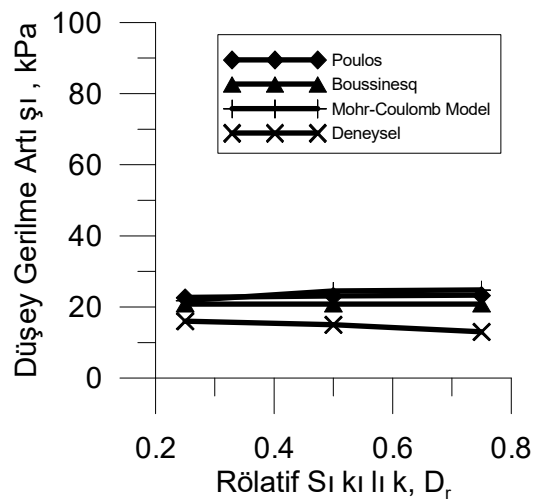

(c)

Şekil 9 - Model temelin orta noktası altındaki düşey gerilme artışları (a) $z / B=1$, (b) $z / B=2$, (c) $z / B=3$

Temellerin oturmalarının hesabında bitişik temeller arasında etkileşim önemlidir. Model şerit temelden $\mathrm{x} / \mathrm{B}=1$ yatay mesafe altında bulunan 2, 5 ve 7 No'lu basınç ölçerlerde ölçülen düşey gerilme artışı ile Mohr-Coulomb modeli, Boussinesq ve Poulos çözümleri ile hesaplanan düşey gerilme artışlarının rölatif sıkılık ile değişimi Şekil 10'da görülmektedir. Deneysel ölçümlerde, model temel altında bulunan basınç ölçerlerde rölatif sıkılık arttıkça gerilme artışları azalırken, $\mathrm{x} / \mathrm{B}=1$ uzakta bulunan basınç ölçerlerde gerilme artışları rölatif sıkılıkla birlikte artmaktadır. Poulos çözümü deneysel ölçümlere en yakın sonuçları vermektedir. Tüm yöntemler genel olarak değerlendirildiğinde donatılı kum zeminlerde yüklü bölgenin izdüşümü dışındaki gerilme artışları, Poulos çözümü ile en fazla uyum içinde olmaktadır. 
Gerilme dağılışları için yaygın olarak kullanılan Boussinesq çözümü ise donatılı kum zeminlerde en hatalı sonuçları veren yöntemdir.

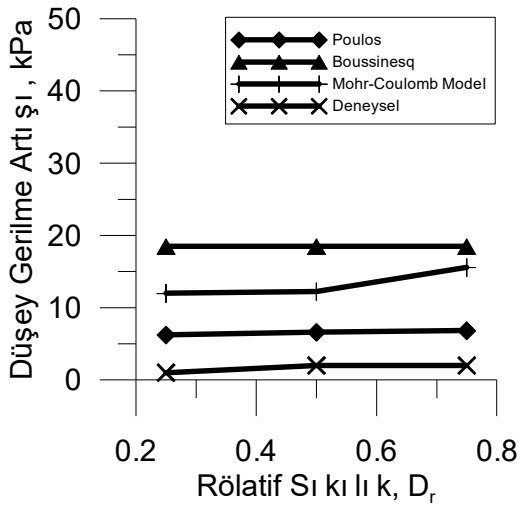

(a)

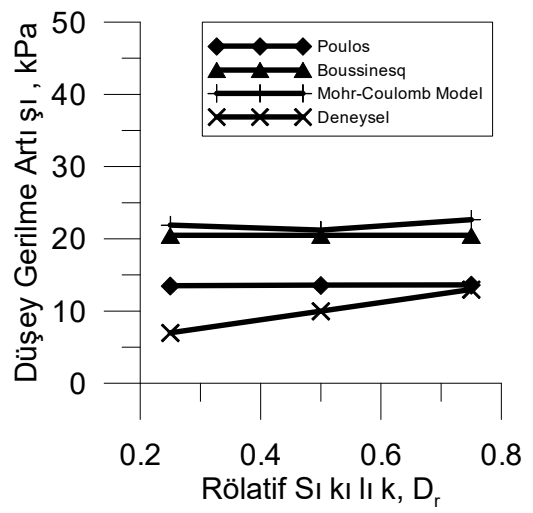

(b)

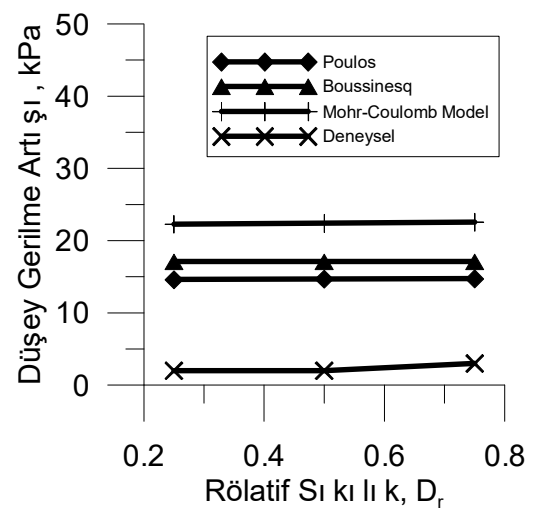

(c)

Şekil 10 - Model temelin yatayda $x / B=1$ mesafedeki düşey gerilme artışları (a) $z / B=1$, (b) $z / B=2$, (c) $z / B=3$

Farklı sıkılıklardaki donatılı kum zemine ait basınç soğanları Şekil 11'da gösterilmektedir. Yüzey yüklerinden etkilenen derinlik olarak tanımlanan anlamlı derinlik Rölatif sıkılık arttıkça azalmaktadır. Fakat tüm rölatif sıkılıklarda, anlamlı derinlik 3B'den daha az olmuştur. Ayrıca rölatif sıkılık arttıkça, basınç soğanı genişlemektedir.
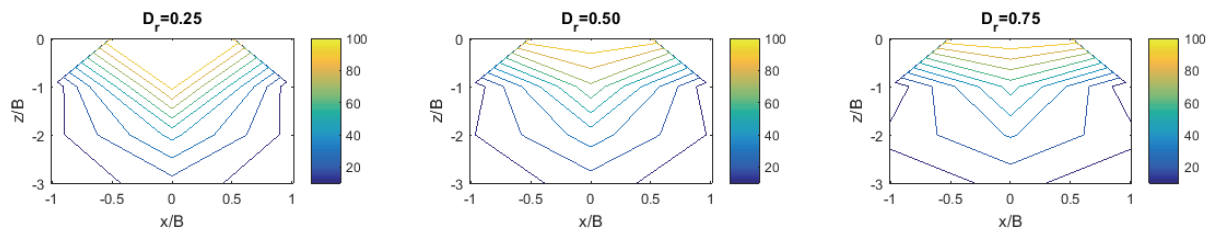

Şekil 11 - Donatılı kum zeminin farklı rölatif sıkılıkları için basınç soğanları 


\section{SONUÇLAR}

Bu çalışmada, donatılı kum zeminlerde düşey gerilme dağılışlarına zeminin rölatif sıkılığının etkisi araştırılmıştır. Bu amaçla, düzlem deformasyon koşullarında yükleme yapan bir deney düzeneği oluşturulmuş ve üç farklı rölatif sıkılıktaki $\left(\mathrm{D}_{\mathrm{r}}=0.25,0.50\right.$ ve 0.75$)$ kuma model temelle yükleme yapılmıştır. Donatılı kum zeminin bazı noktalarına yerleştirilen basınç ölçerler vasıtasıyla düşey gerilme artışları ölçülmüştür. Deneysel olarak düşey gerilme artışlarının ölçüldüğü noktalarda, Elastisite Teorisine dayalı Boussinesq ve Poulos çözümleri ile üniform şerit yük sebebiyle oluşan düşey gerilme artışları belirlenmiştir. Ayrıca, düşey gerilme artışları geoteknik mühendisliğinde sıkça kullanılan elastik ideal plastik MohrCoulomb modeli ile nümerik analiz ile elde edilmiştir. Yapılan bu çalışmalardan aşağıdaki sonuçlar çıkarılmıştır:

- Donatılı kum zeminlerin rölatif sıkılığı arttıkça üniform şerit yüklü bölgenin altındaki düşey gerilme artışları azalmakta ve ilave gerilmeler daha geniş bir alan yayılmaktadır. Rölatif sıkılık, donatılı kum zeminlerde yüzey yükleri sebebiyle oluşan düşey gerilme artışlarının dağılımı üzerinde oldukça etkilidir.

- Yüksek rölatif sıkılığa (Dr $>0.50)$ sahip donatılı kum zeminlerde, yüklü bölgenin altındaki sığ derinliklerde $(\mathrm{z} / \mathrm{B}<2)$ yüzey yüklemesi ile oluşan düşey gerilme artışı, Poulos ve Boussinesq çözümleri ile uyumludur. Düşük rölatif sıkılıklarda ise ölçülen düşey gerilme artışları, Elastisite Teorisine bağlı çözümlerden (Poulos ve Boussinesq) \%50’ye varan oranlarda büyük olabilmektedir. Düşük rölatif sıkılıktaki donatılı kum zeminlerde yüzey yükünden oluşan düşey gerilme artışlarının Elastisite Teorisine dayalı Poulos ve Boussinesq çözümleri ile belirlenmesi uygun değildir.

- Üniform şerit yükün donatılı zemin içindeki izdüşüm alanı dışında kalan noktalarda ölçülen düşey gerilme artışları, Mohr-Coulomb modeli, Poulos ve Boussinesq çözümlerinden oldukça farklıdır. Deneysel ölçümlere en yakın sonuçlar Poulos çözümü ile elde edilmiştir.

- Donatılı kum zeminlerde, rölatif sıkılık arttıkça yüzey yüklerinin etkili olduğu derinlik azalmaktadir.

\section{Semboller}
B : : Üniform şerit yük genişliği
$\mathrm{C}_{\mathrm{r}} \quad$ : Eğrilik katsayısı
$\mathrm{C}_{\mathrm{u}} \quad$ : Üniformluluk katsayısı
$\mathrm{D}_{\mathrm{f}} \quad$ : Temel derinliği
$\mathrm{D}_{\mathrm{r}} \quad$ : Rölatif sıkılık
$\mathrm{D}_{10} \quad$ : Efektif çap
$\mathrm{D}_{30} \quad$ : Tane çapı dağılımı eğrisinde \%30'a karşılık gelen çap
$\mathrm{D}_{60}$ : Tane çapı dağılımı eğrisinde \%60'a karşılık gelen çap 


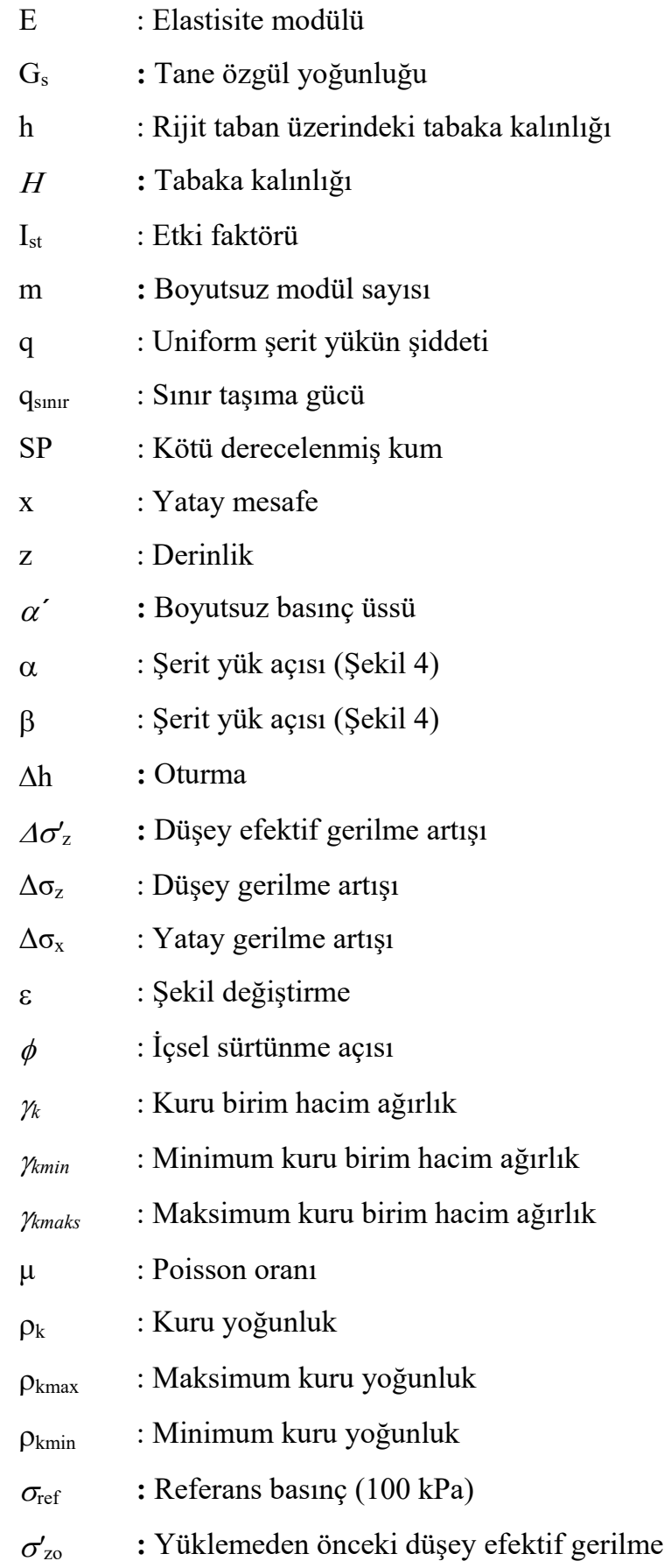




\section{Kaynaklar}

[1] Patel, M.M., Influence od Shape of Footing on The Performance of The Reinforced Sand, Proceedings of The Conference on Construction Practices and Instrumentation in Geotechnical Engineering, 265-269, 1982.

[2] Fragaszy, R.J. ve Lawton, E., Bearing Capacity of Reinforced Sand Subgrades, Journal of Geotechnical Engineering, ASCE, 110, 10, 1500-1507, 1984.

[3] Guido, V.A., Biesiadecki, G.L. ve Sullivan, M.J., Bearing Capacity of a Geotextile Reinforced Foundation, Proceedings of $11^{\text {th }}$ International Conference on Soil Mechanics And Foundation Engineering, San Fransisco, 1777-1780, 1985.

[4] Guido, V.A., Chang, D.K. ve Sweeney, M.A., Comparison of Geogrid and Geotextile Reinforced Earth Slabs, Canadian Geotechnical Journal, 23, 435-440, 1986.

[5] Khing, K.H., Das, B.M., Puri, V.K., Cook, E.E. ve Yen, S.C., The Bearing Capacity of a Strip Foundation on Geogrid-reinforced Sand, Geotextiles and Geomembranes, 12, 351-361, 1993.

[6] Omar, M. T., Das, B. M., Puri, V. K. Yen, S. C., Ultimate bearing capacity of shallow foundations on sand with geogrid reinforcement, Geotechnical Journal, 545-549, 1993.

[7] Das, B. M., Shin, E. C., Omar, M. T., The bearing capacity of surface strip foundations on geogrid-reinforced sand and clay-A comparativestudy, Geotechnical and Geological Engineering, 12, 15-33, 1994.

[8] Tan, Ö. ve Çelik, S., Geogrid Donatılı Kumlarda Taşıma Gücünün Model Deneylerle Araştırılması, 10. Mühendislik Sempozyumu, Süleyman Demiral Üniversitesi, Bildiriler Kitab1, Isparta, 414-420, 1999.

[9] Shin, E.C. ve Das, B.M., Experimental Study of Bearing Capacity of A Strip Foundation on Geogrid Reinforced Sand, Geosynthetics International, 7, 1, 59-71, 2000.

[10] Shin, E.C., Das, B.M., Lee, E. S. ve Atalar, C., Bearing Capacity of Strip Foundation on Geogrid-Reinforced Sand, Geotechnical and Geological Engineering, 20, 169-180, 2002.

[11] Patra, C.R., Das, B.M. ve Atalar, C., Bearing Capacity of Embedded Strip Foundation on Geogrid-Reinforced Sand, Geotextiles and Geomembranes, 23, 5, 454-462, 2005.

[12] Patra, C.R., Das, B.M., Bhoi, M. ve Shin, E.C., Eccentrically Loaded Strip Foundation on Geogrid-Reinforced Sand, Geotextiles and Geomembranes, 24, 254-259, 2006.

[13] Omar, M.T., Ultimate Bearing Capacity of Eccentrically Loaded Strip Foundation on Geogrid- Reinforced Sand, University of Sharjah Journal of Pure and Applied Sciences, 3, 2, 35-51, 2006.

[14] Sadoglu, E., Cure, E., Moroglu, B. ve Uzuner, B. A., Ultimate Loads for Eccentrically Loaded Model Shallow Strip Footings on Geotextile-Reinforced Sand, Geotextiles and Geomembranes, 27, 3, 176-182, 2009. 
[15] Cicek,E., Guler, E., Yetimoglu, T., Effect of reinforcement length for different geosynthetic reinforcements on strip footing on sand soil, Soils and Foundations, Volume 55, Issue 4, 661-677, 2015

[16] Terzaghi, K., Theoretical Soil Mechanics, John Wiley and Sons Inc., New York, 510, 1943.

[17] Janbu, N., Settlement calculations based on the tangent modulus concept. University of Trondheim, Norwegian Institute of Technology, Geotechnical Institution, Bulletin 2, 57 p., 1967.

[18] Fellenius B.H., Basics of Foundation Design, 36-51, 2006.

[19] Binquet, J. ve Lee, K. L., Bearing Capacity Tests on Reinforced Earth Slabs, Journal of the Geotechnical Engineering Division, ASCE, 101, 12, 1241-1251, 1975.

[20] Adams, M.T. ve Collin J.G., Large Model Spread Footing Load Tests on Geosyntetic Reinforced Soil Foundations, Journal of Geotechnical and Geoenviromental Engineering, 123, 1, 66-72, 1997.

[21] Alawaji, H.A., Settlement and Bearing Capacity of Geogrid Reinforced Sand over Collapsible Soil, Geotextiles and Geomembranes, 19, 75-88, 2001.

[22] DeMerchant, M.R., Valsangkar, A.J. ve Schriver, A.B., Plate Load Tests on Geogrid Reinforced Expanded Shale Lightweight Aggregate, Geotextiles and Geomembranes, 20, 173-190, 2002.

[23] Michalowski, R.L., Limit Loads on Reinforced Foundation Soils, Journal of Geotechnical and Geoenviromental Engineering, ASCE, 130, 4, 381-390, 2004.

[24] Wayne, M.H., J.Han and K. Akins, The desing of geosynthetic reinforced foundation, In: Proceedings of ASCE's Annuals Convention and Exposition, ASCE Geotechnical Special Publication, 1-8, 1998.

[25] Kost, A.D., Filz, G.M., Cousins, T., Brown, M.C., Full-scale investigation of differential settlements beneath a geosynthetic-reinforced soil bridge abutment, Transportation Research Record, 2462, 28-36, 2014.

[26] Wang, Z.-J., Ma, S.-W., Lu, L., Study of reinforced soil adjusted to differential settlement based on parabolic cable theory, Yantu Lixue/Rock and Soil Mechanics Volume 38, Issue 11, 3319-3324, 3340, 2017.

[27] Boussinesq, J., Application des potentiels a l'etude de l'equilibre et due mouvement des solids elastiques, Gauthiers-Villars, Paris, 1885.

[28] Westergaard, H.M., A problem of elasticity suggested by a problem in soil mechanics: A soft material reinforced by numerous strong horizontal sheets. In Contributions to the Mechanics of Solids, Stephen Timoshenko 60th Anniversary Volume, MacMillan, New York, 260 - 277, 1938.

[29] Newmark, N.M., Simplified computation of vertical stress below foundations. Univ. of Illinois Engineering Experiment Station, Circular 24, Urbana, Illinois, 19, 1935. 
[30] Newmark, N.M., Influence chart for computation of stresses in elastic foundations. University of Illinois Engineering Experiment Station, Bulletin Series 338, Vol. 61, No. 92, Urbana, Illinois, 28, 1942.

[31] Taylor, D.W., Fundamentals of soil mechanics. John Wiley \& Sons, New York, 700, 1948.

[32] Algin, H. M., Stresses from linearly distributed pressures over rectangular areas, Int. J. Numer. Anal. Methods Geomech., 24(8), 681-692, (2000).

[33] Poulos H. G., Stresses and displacements in an elastic layer underlain by a rough rigid base, Ge'otechnique, 17, 4, 378-410, 1967.

[34] Keskin, S., Laman, M., and Baran, T. Experimental determination and numerical analysis of vertical stresses under square footings resting on sand. Teknik Dergi, 19(4), 4521-4538., 2008.

[35] Chen, Q., An experimental study on characteristics and behavior of reinforced soil foundation., Ph.D. dissertation, Louisiana State Univ., Baton Rouge, LA., 2007.

[36] Çicek,E., Guler, E., Yetimoglu, T., Comparison of Measured and Theoretical Pressure Distribution below Strip Footings on Sand Soil, International Journal of Geomechanics, Volume 14, Issue 5, 2014.

[37] ASTM D854-14, Standard Test Methods for Specific Gravity of Soil Solids by Water Pycnometer, ASTM International, West Conshohocken, PA, www.astm.org, 2014.

[38] ASTM D4253-16, Standard Test Methods for Maximum Index Density and Unit Weight of Soils Using a Vibratory Table, ASTM International, West Conshohocken, PA, www.astm.org, 2016.

[39] ASTM D4254-16, Standard Test Methods for Minimum Index Density and Unit Weight of Soils and Calculation of Relative Density, ASTM International, West Conshohocken, PA, www.astm.org, 2016.

[40] ASTM D3080 / D3080M-11, Standard Test Method for Direct Shear Test of Soils Under Consolidated Drained Conditions, ASTM International, West Conshohocken, PA, www.astm.org, 2011.

[41] Kirkpatrick, W. M. ve Yanikian, H. A., Side Friction in Plane Strain Tests, Proceedings of the Fourth South East Conference On Soil Engineering, Kuala Lumpur, Malaysia 76-84, 1975.

[42] Kirkpatrick, W. M. ve Uzuner, B.A., Measurement Errors in Model Foundations Tests, Istanbul Conference on Soil Mechanics, Istanbul, 98-106, 1975.

[43] Plaxis 2D, Manuals. Plaxis Finite Element Code for Soil and Rock Analysis, 2D Version 8.6. (Edited by Brinkgreve R.B.J., Broere W. And Waterman D.) Delft University of Technology \& Plaxis, The Netherlands, 2004. 
